\title{
Brain Calcification Associated with Pseudohypoparathyroidism
}

\author{
Hyunjin Kim, MD¹, H. Alex Choi, MD, MS², Kiwon Lee, $\mathrm{MD}^{2}$, and Sang-Beom Jeon, MD, PhD ${ }^{1}$ \\ 'Department of Neurology, Asan Medical Center, University of Ulsan College of Medicine, Seoul, Korea \\ ${ }^{2}$ Departments of Neurology and Neurosurgery, The University of Texas Medical School at Houston, Houston, TX, USA
}

A 23-year-old, previously healthy woman presented with a first-onset generalized tonic-clonic seizure. Neurological examination was unremarkable. Computed tomography of the brain showed extensive symmetric calcifications in the corticomedullary junctions, basal ganglia, thalami, and cerebellar hemispheres (Fig. 1). Serum laboratory studies revealed levels of calcium $5.7 \mathrm{mg} / \mathrm{dL}(8.6-10.2 \mathrm{mg} /$ $\mathrm{dL})$, phosphorus $4.4 \mathrm{mg} / \mathrm{dL}(3.5-4.5 \mathrm{mg} / \mathrm{dL})$, and parathyroid hormone $151 \mathrm{pg} / \mathrm{mL}(10-65 \mathrm{pg} / \mathrm{mL})$ consistent with pseudohypoparathyroidism. Her clinical features of a round face, short stature, and short fourth and fifth metacarpals suggested pseudohypoparathyroidism type Ia, Albright's hereditary osteodystrophy. ${ }^{1}$ Pseudohypoparathyroidism is one of medical conditions which can be accompanied by brain calcifications, especially strio-pallido-dentate calcinosis. ${ }^{2}$

\section{REFERENCES}

1. Al-Azem H, Khan AA. Hypoparathyroidism. Best Pract Res Clin Endocrinol Metab 2012;26:517-22.

2. Bonazza S, La Morgia C, Martinelli P, Capellari S. Strio-pallidodentate calcinosis: a diagnostic approach in adult patients. Neurol Sci 2011;32:537-45.
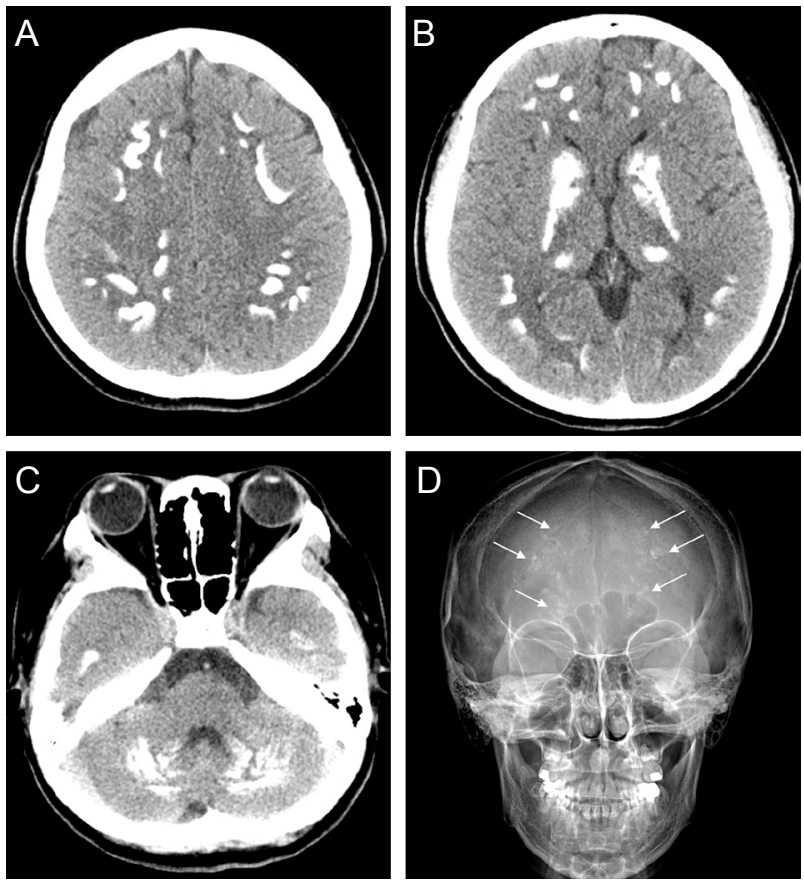

Figure 1. Brain CT demonstrates extensive symmetric calcifications in corticomedullary junctions (A), basal ganglia and thalami (B), and cerebellar hemispheres (C). Calcifications of the brain are also seen in a cranial radiograph (D). Arrows indicate calcifications.

Received: November 16, 2014 / Revised: November 18, 2014

Accepted: November 18, 2014

Address for correspondence: Sang-Beom Jeon, MD, PhD

Department of Neurology, Asan Medical Center, University of Ulsan

College of Medicine, 88 Olympic-ro 43-gil, Songpa-gu, Seoul

138-736, Korea

Tel: +82-2-3010-3440, Fax: +82-2-474-4691

E-mail: sbjeonmd@gmail.com 